\title{
How alkaline solvents in viscosity measurements affect data for oxidatively damaged celluloses. Cupri-ethylenediamine (CED, cuen).
}

Kyujin Ahn, ${ }^{1}$ Sara Zaccaron, ${ }^{1}$ Thomas Rosenau, ${ }^{1,2}$ Antje Potthast ${ }^{1}$ *

${ }^{1}$ University of Natural Resources and Life Sciences, Vienna, Department of Chemistry, Institute for Chemistry of Renewable Resources, Muthgasse 18, 1190 Vienna, and Konrad Lorenz Strasse 24, A 3430 Tulln, Austria

${ }^{2}$ Johan Gadolin Process Chemistry Centre, Åbo Akademi University, Porthansgatan 3, Åbo/Turku FI20500, Finland phone: +43-1-47654-77059, fax: +43-1-47654-77412; e-mail: antje.potthast@boku.ac.at 
Table S1. Overview of the pulps used in the study and their parameters (data provided by the producers).

\begin{tabular}{|c|c|c|c|c|c|}
\hline Acronym & Description & $\begin{array}{c}\text { Kappa } \\
\text { number }^{\text {a }}\end{array}$ & $\begin{array}{l}\text { Brightness } \\
\text { \% ISO }^{\text {b }}\end{array}$ & $\begin{array}{c}\text { Viscosity [CED] }{ }^{c} \\
\mathrm{ml} / \mathrm{g}\end{array}$ & $\begin{array}{l}\mathbf{R}_{18}{ }^{\mathrm{d}} \\
{[\%]}\end{array}$ \\
\hline $\mathrm{CL}$ & Cotton linters & 0.11 & 82.0 & 407 & 98.5 \\
\hline HBSP & $\begin{array}{l}\text { Hardwood (beech) } \\
\text { sulfite pulp - bleached }\end{array}$ & 0.79 & 88.5 & 546 & 93.0 \\
\hline HBKP & $\begin{array}{l}\text { Hardwood (eucalyptus) } \\
\text { kraft pulp - bleached }\end{array}$ & 0.27 & 90.5 & 454 & 97.0 \\
\hline SBSP & $\begin{array}{l}\text { Softwood (spruce) } \\
\text { sulfite pulp - bleached }\end{array}$ & 0.55 & 91.4 & 539 & 94.1 \\
\hline
\end{tabular}

${ }^{\mathrm{a}}$ TAPPI test method T236 cm-85; ${ }^{\mathrm{b}}$ TAPPI test method T452 om-98; ${ }^{\mathrm{c}}$ SCAN CM 15:99; ${ }^{\mathrm{d}}$ DIN 54355.

\section{Preliminary tests with non-oxidized pulps}

In order to validate the regeneration approach used and investigate the effect of CED also on native (i.e., "original", non-intentionally oxidized) samples, preliminary tests were performed. We first compared the molar masses of the native pulps with and without regeneration from DMAc/LiCl 9\% $(w / v)$ to rule out any influence of the regeneration/redissolution process.

When the molar masses of four different DMAc/LiCl-regenerated native pulps (Table S1) were compared to the molar masses of the same pulps without regeneration, very similar results were obtained as shown by the slope being almost exactly 1 in the Mw-Mw plot, as presented in Fig. S1 (red). This verified that $\mathrm{DMAc} / \mathrm{LiCl} 9 \%$ (w/v) did not cause any significant degradation of the pulps during dissolution and the regeneration approach is safe to use.

By contrast, the same pulps regenerated after dissolution in CED clearly exhibited some degradation (Fig. S1, blue). CL, which contains few carbonyl groups in its native state, did not show significant degradation. However, the other native bleached pulps, which contained around 5 to $23 \mu \mathrm{mol} / \mathrm{g}$ of carbonyl groups, suffered from a decrease in Mw upon dissolution in CED. The extent of this decrease was correlated to the carbonyl group contents, that is, the higher the $\mathrm{DO}$, the more intense the 
degradation, as shown by the slope, significantly lower than 1, in the Mw-Mw plot. This issue has been discussed more in detail in the paper along with the results from the deliberately oxidized pulp samples.

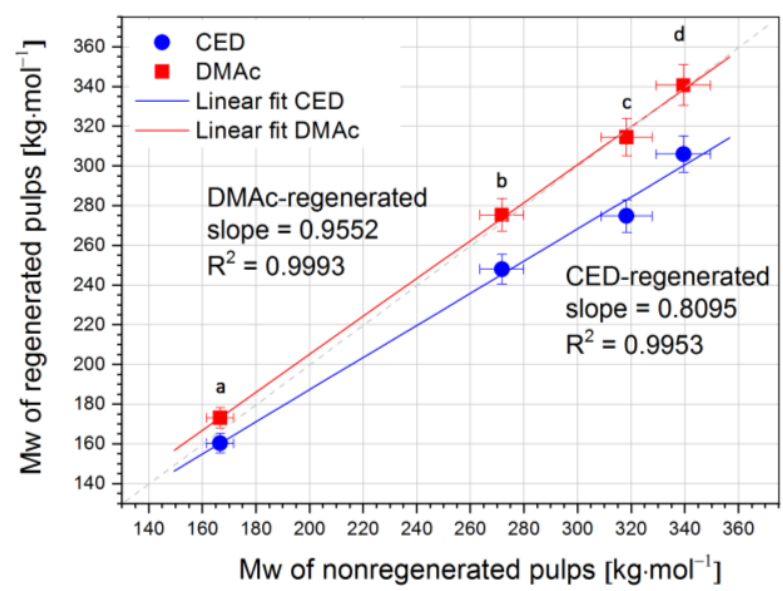

Fig. S1 Molecular weights (Mw) of four different native pulps. Comparison between original pulps and their counterparts regenerated from DMAc/LiCl 9\% (red) and CED (blue). Pulps: (a) CL; (b) SBSP; (c) HBKP; (d) HBSP.

Furthermore, we investigated the dissolution process in CED with regard to the structure of the fibers, in time-course experiments. In a previous communication, we already showed that the extent of cellulose degradation by CED was dependent on the dissolution time in CED when an HBSP was tested; the longer the dissolution time, the lower the molar mass ${ }^{1}$. Here (Fig. S2), we additionally display how the CL fibers (top) and the HBSP fibers (bottom) behave visually in contact with CED. The CL fibers look longer, more twisted, and curlier as compared to the HBSP fibers, which appear short and straight with sharp ends. These structural features of the fibers seem to influence the dissolution time of the pulps in CED. An isolated CL fiber completely vanished within 10 seconds while, for a thin and short HBSP fiber, the dissolution was even faster (within 5 seconds). Aggregated fiber bundles dissolved fast as well (less than 5 and 3 minutes for HBSP and CL, respectively).

\footnotetext{
${ }^{1}$ Ahn, K.; Henniges, U.; Potthast, A.; Rosenau, T., Influence of solvents used for viscometry on oxidized cellulose: Influence of CED on various pulps. In 18th International Symposium on Wood, Fibre and Pulp Chemistry (ISWFPC) September 8-11 2015, Eds. Hell, J., Böhmdorfer, S, Potthast, A, Rosenau, T, Ed. Vienna, Austria, 2015; Vol. II.
} 

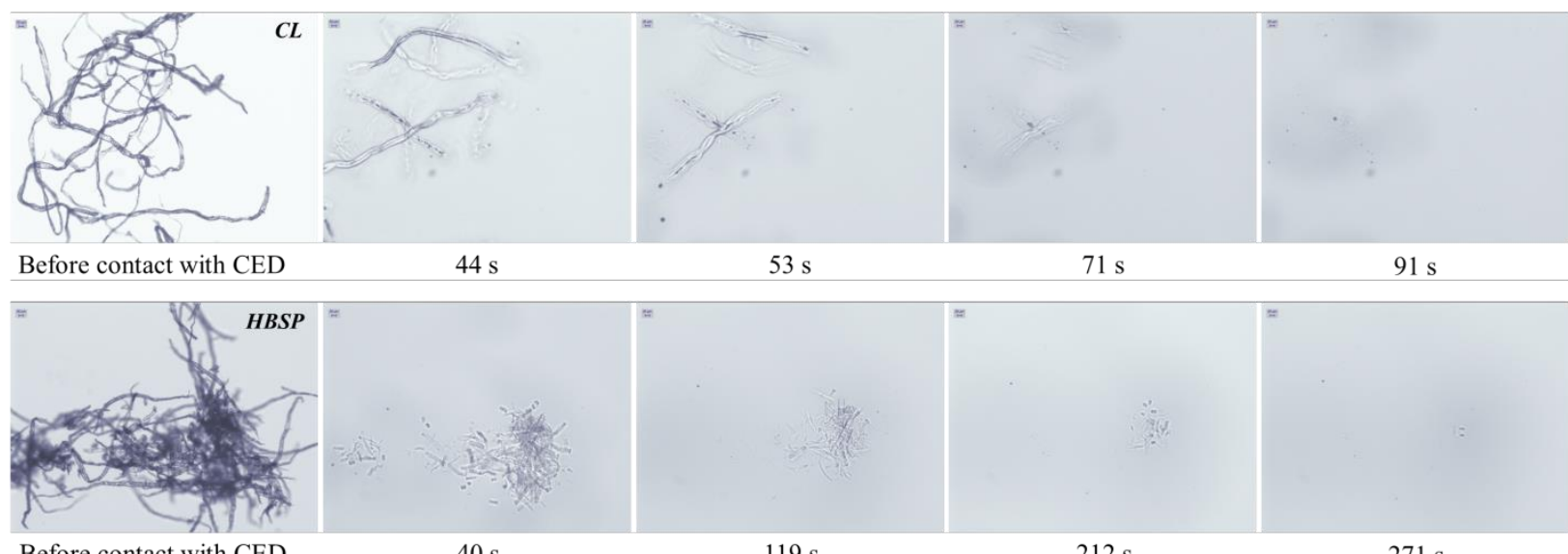

55

It can be concluded that:

- The regeneration/redissolution approach works reliably;

- Cellulose degradation in CED is evident also on native (i.e., "original", non-intentionally oxidized) samples, and it seems dependent on the pulp type. A pure-cellulose pulp, such as CL, shows no significant change in Mw while a bleached wood pulp, such as HBSP degrades significantly with remarkable loss of hemicellulose 